\title{
Environmental Educational Youth Action Task Program
}

\author{
Nik Norulaini Nik Ab Rahman, (Email: norulain@usm.my), School of Distance Education, Malaysia \\ Fatehah Mohd Omar, School of Industrial Technology, Malaysia \\ Noorliza Kalia, School of Management, Universiti Sains Malaysia, Malaysia \\ Mohammad Hasmi, School of Distance Education, Malaysia
}

\begin{abstract}
An educational environmental youth camp was held comprising of fifty one 16-year old secondary students and facilitated by volunteers from the university and Friends of the Earth, a non profit organization in Penang. A weekend camp on youth action task program was held at an isolated beach packed with activities that were structured towards environmental good sense. Five activities were conducted with the volunteers as moderators. The main objective of the camp was to create more perceptive understanding on the environmental importance to the community, and the need for the community to protect the environment. The students were brought to the realms of nature and issues currently plaguing our towns, cities and countryside. With the coming in contact with nature, the veracity of the environmental issues was infused into the students. The activities began with an ice breaking sessions with the facilitators, jungle trekking, 'life chain', 'issues and its realities', 'action plan' and wrapped by developing resolutions. Each of these activities were practical learning and fun filled experiences that were well guided by facilitators who were themselves dedicated volunteers in the youth action task program. The program ended with meeting the teachers at the respective schools to further develop the activities at school, interschool, and community and intercommunity levels. It is also hoped that these students will be able to be continuously be active in the youth action task program and be the advocates and proponents to support the environment.
\end{abstract}

\section{INTRODUCTION}

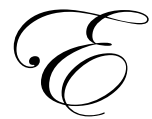

nvironmental education has not been given much attention in the school syllabus. In majority of the cases, environmental education is not considered academic enough to deserve greater attention. It has however been subtly incorporated into science or humanities subjects such as geography. Environment as a subject matter has however been thoroughly dealt with at the tertiary level where there are copious research and development in the area. The are many tertiary level courses that have been offered across many disciplines ranging from engineering to pure sciences as well as social sciences and humanities. These are the academic approaches with all its theories and scientific facts. The question then arises as to how this can be simplified and make a layman understand and incorporate it in his daily lives.

There are also practices in many countries where the attitude to care for the environment were developed at a preschool level (Tilbury, 1994). A child or a school age student might not be able to understand how he can contribute to make a difference in the world that is now slipping into an irreparable environmental state. Too rigid approach in the lessons taught in schools might not be the right thing for the students to get the reality of the issues besetting the environment. To reach out to the students, they would have to be engaged in the process of understanding, where they should be galvanized to investigate, understand, motivate, sort and take action. Sorting through issues are important because that will lead to the correct course of actions.

The alliance of two generations of youths separated not too far apart in age can provide a powerful forum for environmental pursuit. Likewise, involvement of community adds great thrust to the constructivism in actions. From this, an intergenerational approach to environmental action can be successfully implemented and students will 
come to realize the importance of community involvement (Peterat and Mayer-Smith, 2006). Accordingly an effective environmental education is not a rigid program, nor is there compulsion to follow, but it is an effort that should be integrated into the community capacity building. Successful programs demand a coordinated approach to addressing the essentials in the environmental education and programs designed cannot be operated in isolation. A multitude of alliances with other bodies, private, industrial, governmental or commercial can bring a wealth of knowledge and sharing among the participants. Efforts by governmental bodies frequently failed because local communities and public at large had not been convinced that the long range goals of protecting the rivers, the air and the earth were more valuable than having unstoppable development. It had been hypothesized that through the engagement of children, teenagers and adults in collaborative and cooperative learning, the longer goals can be achieved. In a research by Ballantyne et al (1998), they discovered that many environmental problems are desperately in need of attention and that educating both adults and young people is seen as part of the solution to such problems. Educators have come to terms that environmental change and perception cannot be imposed, because it needs to be driven especially so by a group. Recognizing these interconnected dimensions encourages environmental education that more effectively, practically, and honestly integrates sense of place with real-world issues of environmental learning, involvement, action, and community-based conservation (Ardoin, 2006).

The objectives of this study were to:

1. to establish basic perspective on the environmental threats among the students through mind testing activities

2. to establish an initial environmental picture of the surrounding conditions

3. to comprehend the types of environmental impacts that can arise from the ubiquitous human activities

\section{METHODOLOGY}

1. Jungle trekking

This was one of the activities considered as compulsory during the program that began from the main road up to the camp ground at the beach. All through the trekking, the students were required to infuse the nature and the ecosystem of the surroundings. The students:

i) observed and familiarized with the jungle ambiance,

ii) recognized the relationship between flora and fauna

iii) learned to cherish and appreciate the contribution of the jungle system to the entire environment as a whole

2. Life chain or ecological cycle

Ecology subsumes the interdependence of life organism (biotic) such as plants and animals and the abiotics such as air, water, earth. This activity brought to light the intricacy of the interdependency of one organism onto another. Students were to fathom

i) the elements that exist in the environment

ii) the interrelationship of each element

iii) the diverse ecosystem

3. Issues and reality

Issues and reality involved an activity that 'created' real situations based on a list of environmental events that were being distributed to the participants. The participants had to take up certain perspectives on the current environmental issues, while being exposed to the concept of environmental care and attention. There were:

i) Group discussions to work on the list of environmental issues and its sources and impacts

ii) Role play involving a dramatic situation involving community and environment 
4. Issues and reality based on current events

Issues printed in the media were discussed and in depth understanding of the reasons why such issues occurred and steps to be taken to prevent the repeat of such uneventful incidences. The participants were encouraged to be more discerning and perceptive on the current environment related events around the nation. Such media coverage puts in the limelight issues that might otherwise slipped the public's attention and were taken up by the participants for further deliberation and scrutiny. The activities or sources that spawned such impacts were diagnosed and probed.

\section{Plans of action}

This activity trained and guided the participants on ways to channel suggestions, complaints or reports on environmental impacts, incidences, policy, guidelines or practices. This was crucial since it encourages personal involvement and creates a sense of aptitude and develops the propensity to act or take action as a contribution to the environment. Actions can take up proactive or reactive mode, personal or community. Participants were

i) trained on their rights, roles and responsibilities

ii) guided on the techniques and ways to address environmental issues on a personal or community basis

iii) divided into groups for discussion on specific issues

6. Meetings with the teachers

At the end of the educational camp, resolutions were established to propagate the youth action task program, to call for dedicated volunteers from among these students. Meetings with the teachers discussed the activities conducted during the program and discover ways to promulgate these ideas to other students and the community. These ideas and the youth task action groups are needed to be the campaigner or champion for the environment.

\section{RESULTS AND DISCUSSION}

In this environmental education program, young adults from a local university as well as volunteers from a non profit organization had joined force to work with teenage students in endearing them with an outdoor environmental program. It is an alliance of two groups of young people with certain age difference and level of academic exposure and background. This partnership program creates a healthy and galvanizing atmosphere for the two parties to work with certain level of closeness in the relationships. According to Dellmann-Jenkins, (1994), it is important for younger persons, who are in the formative period of development and direction, to experience the benefits of positive interaction with older persons. Program evaluation findings showed that participation was influenced by the increased willingness to accept older persons on social and academic levels.

The jungle trekking was aimed at bringing the participants through a nature's trail that was developed by the Forestry Department of Penang and is an induction into nature's embrace. Bixler et al (1994) discovered that some urban children develop fears and discomfort on fieldtrips in the wild land. Activities at specific 'checkpoints' were conducted along the trail, including creating rhymes that link the ecological components. Such rhymes:

'The green forest;

Home to flora and fauna;

The monkeys, the birds, the tigers

The chengal, the meranti and the angsana (types of tropical trees)

The green forest

Reaching high into the sky

Look up, see you not the canopy

That provides shades to rest' 
The trek ended at the camp ground along a pristine beach, the students were enthralled by the jungle, the abode of a multifarious species of flora and fauna. The fascination was enhanced with a clear and more intimate examination of the ecological structures that made up every section of the trail that they passed through. Students were urged to note down observations on the biodiversity of flora and fauna and its interdependence on each other. The trek took an average of three hours, ending up at a lagoon with wetland covering the adjacent area. A boardwalk provided access across the wetland which transformed from a swamp to a dried up piece of land within a single day. The students were divided into smaller groups to go through their trekking experience and delve into their observations by creating a web of relationships in the ecological system. The objectives were to advocate the students to look deeper into nature than just trees and undergrowths. Students were encouraged to think and imagine a world without forest or jungles. Using a jungle vocabulary, students inadvertently had their biology lessons, hands on. Watson (2006) investigated conceptions of nature and the role of place in environmental education in children who attended natures camp where he used structured "nature programs" and unstructured "free-play," where the children discovered and increased their familiarity of common local animals.

The students were able to develop relationships between the ecological components and amplify their perspective of the nature around them. 'Nature and I' was an activity where students were asked to select an object of nature that represents them and explain why. This activity very much spawns the idea of responsibility and each individual has a role in the protection of the environment. Such imagination of being an inherent part of nature will develop a deeper sense of gratitude for the nature around. As an example "I am a tree and I am a principal component of the jungle; I provide shade and abode for birds and many mammals and reptiles. My leaves emit oxygen for human consumption and carbon dioxide to maintain the earth gaseous balance.' From such an exercise, the students understand the role of each ecological component. Other researchers such as Miles (1986) and Partridge (1984) had used nature as part of the learning place to understand environment.

In the ecological cycle, students are made to comprehend its meaning which the definition can be construed as the interdependence of all things dead or alive within a given natural habitat system. Ecology is a biological branch that studies the relationship between the life organisms and the surrounding. Students began to learn all the other elements of nature, and understand the biodiversity of the ecosystem.

In issues and reality, students were given a list of environmental issues and to discuss the list. Group discussions were held and students were exposed to the current information on the environment, community and nation. Examples of the list of activities and its impacts distributed to the students were: Logging activities, burning of the forests, transforming forest land to agriculture and township and construction of dams and reservoirs. The subsequent impacts are soil erosion, mud flood, river siltation, threatened aquatic life, microclimatic change and sociological impacts. A role play was conducted involving individuals who represented 'the local authorities', 'the local government', 'the federal government', 'the contractors', 'the locals', 'the media' and 'the public at large'. By assuming these roles, the weaknesses in the system were highlighted and further discussed to get to the root of the problems. By dissecting the issues deeper, the students came closer to understanding the real cause of the problems and in such cases, taking actions would be the next course of approach.

A second type of 'Reality issues' put forward to the students encompassed those printed in the print media. These incidences were distributed to the students to be appraised and find its causes and solutions. The incidences selected were national issues that need to be dealt at the local or national level. Understanding what causes the event to take place will lead to finding solutions. The students were guided along the process of understanding the activities and aspects of those activities that lead to such impacts or incidence. The nature, intensity and probability of such impacts taking place were also discussed in the groups. At the end of the activities, the students were able to comprehend the extent of human activities to create impacts that are detrimental to the surroundings as well as to the nation and that many of these activities are bound by law.

The next set of activities under 'Plan of Action' was meant to guide the students into ways and avenues to channel their complaints, ideas or reports to the relevant parties. With the assistance from the facilitators, the students were divided into groups to look into the list of the types of actions that can be taken up by individuals, societies or communities. Among the course of actions delineated include, education and seminar, field community 
activities, writing to local authorities, political representatives, and media, exhibition and competition in schools, and environmental debates. The choice of approach depends on the urgency of the matter, the audience, the financial support, and the level of participation among other things. The students were steered according to the issues to be addressed as well the criteria aforementioned. Given a certain issue, students were inspired and encouraged to come up with a mode of action deemed apt for the issue in hand. The output from this activity is that the students will be savvier in ways to play a part in the environmental issues on hand. This creates a level of confidence and conviction that matters that are of national interest such as environment can be approached from efforts made by an individual or groups of individual. Students were also aware of the organizations, bodies or individuals that can be the most apt avenues to voice out ideas, suggestions or complaints. Every individual in the community has a role to play in addressing the environmental issues and that the different techniques or approaches revealed that the resources and outlets are inexhaustible. According to Fontes (2004), the comprehensiveness of action competence allows and requires that environmental education integrate separate and sometimes opposing approaches: knowledge, in the form of knowhow, of how to act, individually and collectively, to bring about change; and the will to act, about the environment and about society. listed below:

At the end of the environmental camp program, the students made up a list of resolutions and these are

- $\quad$ will apply the knowledge in the conservation and protection of the environment

- $\quad$ will be fair and truthful in environmental action plans undertaken

- $\quad$ apply and practice the competency learned from the action plan

- $\quad$ will spread the environmental awareness and concerns to other youths

- $\quad$ will participate in any environmental based activities

- will commit with other youths and communities to uphold the integrity of the environment

Finally, a school meeting was held with the teachers where the teachers were to work with their students that participated in the environmental camp on how to share the experience and knowledge gained during the program. The intention was to involve more students in the programs, especially the youth task action program that can be developed in the schools, or in collaboration with other schools, community, institutions or organizations.

\section{ACKNOWLEDGEMENT}

The authors would like to extend their appreciation to the Ministry of Science, Technology and Environment for the 3 year-research grant awarded to conduct this study. A heartfelt gratitude is also directed to the Penang State Department of Forestry for providing the camp ground, Penang State Department of Wildlife for providing the tents and other camping facilities and the Penang State Department of Fisheries for providing the boat to carry the supplies to the isolated beach.

\section{REFERENCES}

1. Ardoin, N. A., (2006), Toward an Interdisciplinary Understanding of Place: Lessons for Environmental Education, Canadian Journal of Environmental Education, Vol 11, No 1, pp 112-126

2. Ballantyne, R., Connell, S., Fien, J. (1998) Students as catalysts of environmental change: a framework for researching intergenerational influence through environmental education, Environmental Education Research 4(3), pp. 285-298

3. Bixler, R., Carlisle D. L., Hammitt, W. E., \& Floyd, M. F. (1994). Observed fears and discomforts among urban students on field trips to wild land areas. The Journal of Environmental Education, 26 (1), 24-33. [EJ 496 836].

4. Dellmann-Jenkins, M., Fowler, L., Lambert, D., Fruit, D., \& Richardson, R. (1994). Intergenerational sharing seminars: Their impact on young adult college students and senior guest students. Educational Gerontology, 20, 579-588.

5. Fontes, P. J., (2004), Canadian Journal of Environmental Education, Action Competence as an Integrating Objective for Environmental Education, Vol 9, pp148-162 
6. Gallagher, J., C. Wheeler, M. McDonough and B. Namfa, (2000) Sustainable Environmental Education for a Sustainable Environment: Lessons from Thailand and Other Nations, Water, Air, and Soil Pollution, 123:489-503

7. Miles, J. C. (1986). Wilderness as a learning place. Journal of Environmental Education, 18 (2), 33-40. [EJ $356038]$.

8. $\quad$ Patridge, E. (1984). Nature as a moral resource. Environmental Ethics, pp.101-130.

9. Peterat, L. \& Mayer-Smith, J. (2006). Farm friends: Exploring intergenerational environmental learning. Journal of Intergenerational Relationships, 4(1), 107-116.

10. Tilbury, D. (1994). The critical learning years for environmental education. In R.A. Wilson (Ed.). Environmental Education at the Early Childhood Level. Washington, DC: North American Association for Environmental Education, pp. 11-13.

11. Watson, G. P. L. (2006), Wild Becoming: How the Everyday Experience of Common Wild Animals at Summer Camp Acts as an Entrance to the More-than-Human World Canadian Journal of Environmental Education, Vol 11, No 1, pp 127-142

\section{$\underline{\text { NOTES }}$}

